\title{
Characterization of Isolates of Phytophthora infestans from Southern and Southeastern Brazil from 1998 to 2000
}

\author{
Ailton Reis, Departamento Fitopatologia, Universidade Federal de Viçosa (UFV), 36570-000 Viçosa-MG, Brazil; \\ Christine D. Smart and William E. Fry, Department of Plant Pathology, Cornell University, 334 Plant Science, \\ Ithaca, NY 14853, USA; Luiz A. Maffia and Eduardo S. G. Mizubuti, Departamento Fitopatologia, UFV, Brazil
}

\begin{abstract}
Reis, A., Smart, C. D., Fry, W. E., Maffia, L. A., and Mizubuti, E. S. G. 2003. Characterization of isolates of Phytophthora infestans from southern and southeastern Brazil from 1998 to 2000. Plant Dis. 87:896-900.

The population of Phytophthora infestans in Brazil was first characterized 12 years ago. In this research, isolates of $P$. infestans from potato $(n=184)$ and tomato $(n=267)$ collected in southern and southeastern Brazil were characterized to provide more detailed analysis of the current structure of the population. All 451 isolates were analyzed for mating type, and subsets of the isolates were analyzed for allozymes, restriction fragment length polymorphism fingerprint, mtDNA haplotypes, and metalaxyl resistance. Tomato isolates were all of A1 mating type, mtDNA Ib, and US-1 genotype or some variant within this clonal lineage. Of the potato isolates, $82 \%$ were A2 mating type, mtDNA IIa, BR-1 genotype, which is a new lineage of $P$. infestans. All A2 isolates were found on potato, whereas $91 \%$ of the A1 isolates were from tomato. A1 and A2 isolates were never found in the same field. The frequency of resistance to metalaxyl was higher in isolates from tomato (55\%) than in isolates from potato (38\%). After more than a decade of coexistence of isolates of the A1 and A2 mating types, the population was highly clonal, dominated by the BR-1 and US- 1 clonal lineages.
\end{abstract}

Tomato (Lycopersicon esculentum Mill.) and potato (Solanum tuberosum L.) are the two most important vegetable crops in Brazil. Approximately 3 million metric tons of tomato and 2.6 million tons of potato were produced in 2000 (21), mainly for fresh market consumption. Processing tomato is becoming an important commodity in Central Brazil, where large acreages are being cultivated. Meanwhile, potato crops grown for the chip industry still are restricted to contracted growers. Tomato production areas are located in many states throughout the country (Fig. $1 \mathrm{~A})$, whereas potato is cultivated mainly in southeastern and southern Brazil (Fig. 1B). Together, the two regions account for 62 and $96 \%$ of total production of tomato and potato, respectively.

Late blight caused by the oomycete Phytophthora infestans (Mont.) de Bary is a highly destructive disease for both potato and tomato crops in Brazil. The disease is especially important in the southeast and southern regions, where weather conditions in some areas favor late blight devel-

Corresponding author: E. S. G. Mizubuti E-mail: mizubuti@ufv.br

Present address of A. Reis: Embrapa Hortaliças, C. Postal 218, 70359-970 Brasilia-DF, Brazil.

Accepted for publication 5 March 2003

Publication no. D-2003-0522-03R

(C) 2003 The American Phytopathological Society opment almost all year round. Late blight control is estimated to be $20 \%$ of the total production costs and fungicide spraying is the most commonly adopted control measure (26). Large amounts of protectant and systemic fungicides are used to control late blight and the consequences of irrational use of chemicals concern environmentalists, society at large, and growers. There have been complaints about reduction in efficacy of fungicides, mainly metalaxyl, in controlling the disease. Poor plant coverage and changes in the pathogen population with occurrence of resistant isolates could be responsible for the reduction in fungicide efficacy.

The population of $P$. infestans affecting potato and tomato in Brazil was characterized $(1,15)$ immediately after the migration of genetically distinct isolates outside the Toluca Valley, Central Mexico, the center of diversity for $P$. infestans, was first reported (15). The pathogen is a heterothallic species with two mating types, A1 and A2 (12), and isolates of the latter type were not reported outside Central Mexico until 1984 (20). Studies carried out during the mid- to late 1980 s revealed a low diversity of Brazilian isolates of $P$. infestans $(1,15)$. At that time, isolates belonging to two clonal lineages were found, US-1 (found mainly on tomato) and BR-1 (found only on potato) (1). These lineages were defined based on DNA fingerprinting, sexual compatibility mating types, isozymes, resistance to metalaxyl, and mitochondrial DNA patterns $(1,11,15,19)$. The US-1 genotype in Brazil had two variants, US1.1 with $86 / 100$ and 100/100 genotypes for isozymes glucose-6-phosphate-isomerase (Gpi) and peptidase (Pep), respectively, and US-1.7 with $100 / 100$ and 92/100 genotypes for $G p i$ and Pep, respectively (15). These studies were conducted with a relatively small number of isolates collected from 1984 to 1987 and DNA fingerprinting analysis was performed on only one isolate each of the A1 and A2 mating types (15).

It is possible that sexual reproduction is now part of the life cycle of $P$. infestans in Brazil, and this may affect disease control strategies. In many southeastern and southern regions, there are several counties where both potato and tomato crops are cultivated and sexual recombination could take place. In these regions, the mixture of inoculum of the populations affecting tomato (A1 mating type) or potato (A2 mating type) could generate a more diverse population of $P$. infestans and eliminate host specificity. Oospores resulting from sexual reproduction $(6,30)$ can play an important role in the epidemiology of late blight. Oospores can serve as survival structures $(25,33,36)$ and progeny derived from them could generate genetically new genotypes that are epidemiologically important (13) and that could compromise the benefits of using resistant cultivars.

A more detailed analysis of the population of $P$. infestans would be of interest from both the basic and applied scientific perspectives. The basic scientific question is related to the pathogen population dynamics in a continuous cropping system. In some regions of Brazil, three crops of potato and tomato can be grown throughout the year, which would be roughly equivalent to 3 years of host-pathogen interaction in temperate climates where usually only one growing season is possible. From the applied perspective, it is important to determine the geographical distribution of $\mathrm{A} 1$ and $\mathrm{A} 2$ isolates, if there is still host specificity, and the frequency and distribution of metalaxyl resistant isolates.

After more than 10 years of coexistence of isolates of both mating types in Brazil, it is possible that there have been major changes in the population structure of $P$. infestans. The objectives of this study were to characterize current populations of $P$. infestans from southern and southeastern 
Brazil to obtain better insight into the population structure of this pathogen. We tested three hypotheses: (i) that there is sexual reproduction of $P$. infestans in Brazil, (ii) that the population of $P$. infestans in Brazil is highly diverse, and (iii) that there is no host specificity within the population of $P$. infestans in Brazil. The approach was to sample potato and tomato fields in southern and southeastern Brazil, to characterize these isolates using a variety of markers and traits, and to identify associations among the markers.

\section{MATERIALS AND METHODS}

Isolates of $P$. infestans. Potato and tomato leaves, stems, fruit, or tubers with typical late blight symptoms were collected from commercial production fields in most of the major potato- and fresh tomatoproducing regions of Brazil from January of 1998 to October of 2000. Additionally, samples from universities and experimental research stations from different states in Brazil also were obtained. Depending on the quality of the sample, isolation was performed either directly on Rye B culture media amended with antibiotics (nystatin, rifampicin, and ampicillin) or using tomato or potato as bait, with subsequent isolation on culture media $(8,9)$. Uncontaminated colonies, determined by visual inspection, were grown on
Rye-B culture media (3) at $18^{\circ} \mathrm{C}$ in the dark. The isolates were characterized for mating type, genotypes at the Gpi and Pep loci, genomic DNA restriction fragment length polymorphism (RFLP) fingerprinting using the RG57 probe, mitochondrial DNA haplotype, and metalaxyl resistance.

Mating type. All isolates were analyzed for mating type. Isolates were paired with known A1 (US-1) and A2 (US-8) tester isolates on $10 \%$ clarified V8 juice agar (32). Mycelial plugs ( $8 \mathrm{~mm}$ in diameter) of a known A1 or A2 isolate were placed on opposite sides of the strip of unknown isolate. A strip ( 5 to $6 \mathrm{~mm}$ in width by 40 to $50 \mathrm{~mm}$ in length) of culture medium containing mycelial growth of a 7- to 10day-old isolate was centered in the plate (90 $\mathrm{mm}$ in diameter), between the two discs. The plates were transferred to an incubator at $18^{\circ} \mathrm{C}$. After incubation for 3 to 4 weeks in the dark, plates were checked microscopically for the presence of oospores where mycelia of the known and unknown isolates intermingled. Isolates that produced oospores when paired with the A1 tester isolate, but did not produce oospores with the A2 isolate were designated A2. Isolates that formed oospores when paired with the A2 tester and did not form when paired with the A1 isolate were designated A1. Mating type was determined for 451 isolates.
Allozymes. The Gpi loci were determined using either cellulose-acetate or starch gel electrophoresis (14), and the Pep loci were determined using only celluloseacetate electrophoresis (17). Mycelia from 7- to 10-day-old colonies grown on rye-B agar (A1 isolates) or pea agar (A2 isolates) were used for allozyme profile analysis using cellulose acetate (17). Mycelial growth of A2 isolates was more abundant on pea agar than on rye-B. Mycelia for starch gel analysis were obtained from cultures grown in $50 \mathrm{ml}$ of pea broth for 10 to 15 days. Allozyme alleles were designated by the numbers representing their percentage of mobility relative to previously established standards (15). A subset of 270 isolates was analyzed for $G p i$ (172 from tomato and 98 from potato) and 113 isolates were analyzed for Pep (67 from tomato and 46 from potato).

DNA fingerprinting (RG57). The DNA extraction protocol and the RFLP analysis using RG57 probe was carried out on 94 isolates using the methodology described by Goodwin et al. (16). The pathogen was grown in pea broth supplemented with $\mathrm{CaCO}_{3}$ for 15 days at $18^{\circ} \mathrm{C}$, as standing culture. The mycelium was filtered through filter paper on a Buchner funnel, frozen at $-80^{\circ} \mathrm{C}$, and lyophilized overnight. Alkaline blotting to Hybond- $\mathrm{N}^{+}$nylon membrane, hybridization with nonradioactive RG57

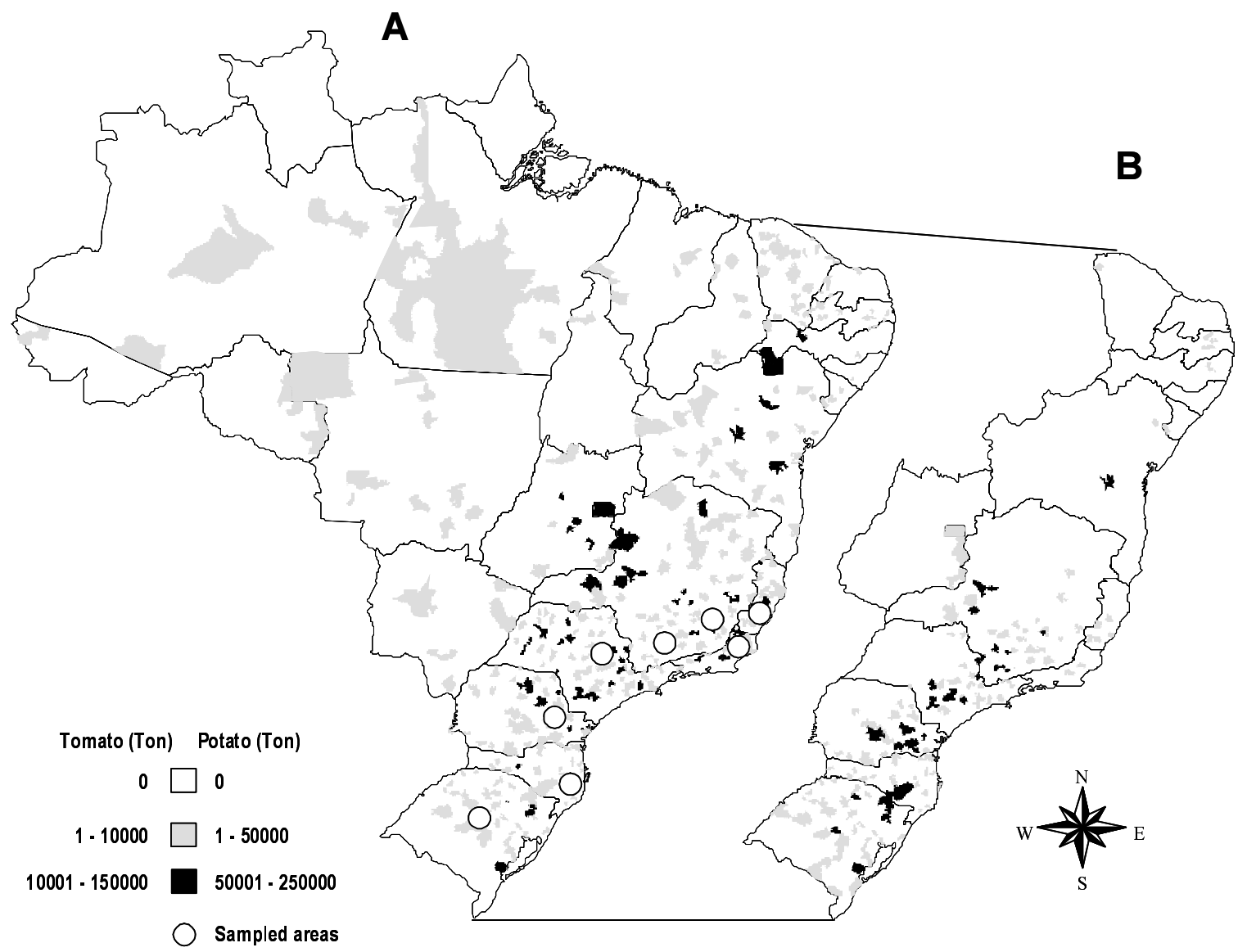

Fig. 1. A, Tomato- and B, potato-growing areas in Brazil and total production. Sampled areas are marked with a circle. Production data compiled from IBGE (21). 
probe, and autoradiography were all according to the manufacturer's instructions (Renascence Kit; NEN Life Science, Boston) and standard protocols (29). The DNA fingerprinting of the isolates was determined by comparing their patterns with those of the three reference isolates (US-1, US-8, and US-17).

Mitochondrial haplotypes. Based on nuclear DNA data, 41 isolates were chosen for analysis of mitochondrial DNA. DNA extraction, digestion with restriction enzyme, polymerase chain reaction, and determination of the four known mitochondrial haplotypes of $P$. infestans (2) were according to Griffith and Shaw (19). The mitochondrial haplotypes of tested strains were determined by comparing their patterns to reference isolates US-1 (Ib) and US-8 or US-17 (IIa).

Metalaxyl resistance. Metalaxyl resistance of 122 isolates was estimated based on radial growth on metalaxyl-amended rye-B agar, as described elsewhere $(5,24,34,35)$. An 8-mm-diameter mycelial plug from a 7-day-old colony was placed on the center of a petri plate containing rye-B amended with metalaxyl (Ridomil 2E; Syngenta Co., Greensboro, NC) at 5 or $100 \mathrm{ppm}$. Control plates were rye-B medium with no metalaxyl $(0 \mathrm{ppm})$. Two replicates of each metalaxyl concentration for each isolate were used. Plates were

Table 1. Number of isolates of Phytophthora infestans collected from tomato and potato regions of Brazil and characterized

\begin{tabular}{lrr}
\hline & \multicolumn{2}{c}{ Host } \\
\cline { 2 - 3 } Region, state & Tomato & Potato \\
\hline South & & \\
Rio Grande do Sul & 1 & 15 \\
Santa Catarina & 18 & 16 \\
Paraná & 19 & 41 \\
Southeast & & \\
São Paulo & 13 & 18 \\
Minas Gerais & 164 & 87 \\
Rio de Janeiro & 29 & 0 \\
Espírito Santo & 23 & 7 \\
Total & 267 & 184 \\
\hline
\end{tabular}

maintained at $18^{\circ} \mathrm{C}$ in the dark. Colony diameter was measured after 14 days, when the diameter of the colony grown at $0 \mathrm{ppm}$ concentration was at least $30 \mathrm{~mm}$. The diameter of the colony was corrected for the diameter of the initial mycelial plug. The mean colony diameter of both plates with metalaxyl at 5 and $100 \mathrm{ppm}$ were divided by the mean colony diameter on the control plates to determine the relative growth. Isolates that grew less than $40 \%$ of the control on metalaxyl plates at 5 and $100 \mathrm{ppm}$ were recorded as sensitive. Isolates that grew more than $40 \%$ of the control on metalaxyl medium at $5 \mathrm{ppm}$ and less than $40 \%$ at $100 \mathrm{ppm}$ were recorded as intermediately resistant. Isolates that grew more than $40 \%$ of the control at both 5 and $100 \mathrm{ppm}$ were recorded as resistant (35). The entire experiment (122 isolates) was repeated once and the mean of both trials is presented in the results.

\section{RESULTS}

A total of 451 isolates of $P$. infestans from individual lesions on diseased tomato foliage and fruit or potato foliage and stems from 132 different fields were obtained. Tomato isolates composed 59\% and potato isolates $41 \%$ of the total number of isolates (Table 1). Of the 132 fields, 51 were cultivated with potato and 81 with tomato. Both A1 and A2 mating types were detected among Brazilian isolates of $P$. infestans that were collected. In all cases, all isolates from the same field were monomorphic for mating type.

All tomato isolates were of the A1 mating type. Of the 67 tomato isolates analyzed for both Gpi and Pep, 63 had the allozyme genotype of the US-1 clonal lineage (86/100 and 92/100). Two isolates (4.5\%) were $86 / 100$ for Gpi and 100/100 for Pep, similar to US-1.1 lineage. One additional genotype, Gpi and Pep 100/100, was detected in one tomato field from Minas Gerais State (BR980070). The Gpi profile of the 105 tomato isolates not analyzed for Pep was 86/100 (103 isolates) and 100/100 (2 isolates) (Table 2).
Most of the potato isolates (82\%) were A2 mating type. The isozyme profile of 40 potato isolates $(40.8 \%)$ was $100 / 100$ for both Gpi and Pep, the same as previously reported for BR-1 lineage (15). Four potato isolates $(4.1 \%)$ from the Horticulture Experimental Area of Universidade Federal de Viçosa, were the A1 mating type, 86/100 for Gpi and 92/100 for Pep, typical of the US-1 genotype. Two potato isolates from the same area were A1, and had 86/100 and 100/100 for Gpi and Pep, respectively. Of the potato isolates that were tested for Gpi and not for Pep, 52 had the Gpi genotype 100/100 (40 A2 isolates) and $86 / 100$ (11 A1 isolates) or 100/100 (one A1 isolate) (Table 2).

The results of the DNA fingerprinting analysis of 93 isolates ( 39 from potato and 54 from tomato) agreed with allozyme analyses and revealed a very uniform structure of the population of $P$. infestans in Brazil. Among the 93 isolates tested, there were five distinct RG57 banding patterns that differed by one to five RFLP loci (Table 2). Tomato isolates belonged to the US-1 clonal lineage, with six variants differing in only one locus (band 9 or 10). In all, 7 potato isolates belonged to the clonal lineage BR-1 (15), but 27 isolates belonged to one possible variant missing band number 22 (Fig. 2). Three potato isolates, from Viçosa, MG, had an RFLP pattern similar to the tomato isolates (Table 2).

Only two mitochondrial DNA haplotypes were found among 41 Brazilian isolates of $P$. infestans tested. The mtDNA of all A1 isolates had the Ib haplotype, typical of the US-1 clonal lineage. The A2 isolates had the haplotype IIa, typical of the newly introduced lineages.

Of 122 isolates tested, 79 isolates $(64.8 \%)$ were ranked as either intermediately resistant (59 isolates, $48.4 \%$ ) or resistant (20 isolates, $16.4 \%$ ) to metalaxyl. Only 43 isolates $(35.2 \%)$ were sensitive to metalaxyl. Metalaxyl resistance was more frequently found among tomato isolates than among potato isolates. Of the 74 tomato isolates, $12(16.2 \%)$ were intermedi-

Table 2. Genotypes of Phytophthora infestans detected in potato and tomato in southern and southeastern Brazil from 1998 to 2000

\begin{tabular}{|c|c|c|c|c|c|}
\hline \multirow[b]{2}{*}{ Host, mating type } & \multirow[b]{2}{*}{ Gpi } & \multirow[b]{2}{*}{ Pep } & \multirow{2}{*}{$\begin{array}{c}\text { Characteristic }^{\mathbf{a}} \\
\text { RG57 }\end{array}$} & \multirow[b]{2}{*}{ Genotype } & \multirow[b]{2}{*}{ No. of isolate } \\
\hline & & & & & \\
\hline \multicolumn{6}{|l|}{ Tomato } \\
\hline A1 & $86 / 100$ & $92 / 100$ & 1010101011001101000110011 & US-1 & 44 \\
\hline A1 & $86 / 100$ & $92 / 100$ & 1010101001001101000110011 & US-1.3 & 5 \\
\hline A1 & $86 / 100$ & $92 / 100$ & 1010101010001101000110011 & US- 1.2 & 1 \\
\hline A1 & $86 / 100$ & $100 / 100$ & 1010101011001101000110011 & US- 1.1 & 2 \\
\hline A1 & $86 / 100$ & $100 / 100$ & 1010101010001101000110011 & US- 1.4 & 1 \\
\hline A1 & $100 / 100$ & $100 / 100$ & 1010101011001101000110011 & RU-1 & 1 \\
\hline \multicolumn{6}{|l|}{ Potato } \\
\hline A1 & $86 / 100$ & $92 / 100$ & 1010101011001101000110011 & US-1 & 3 \\
\hline A1 & $86 / 100$ & $100 / 100$ & 1010101001001101000110011 & US-1.9 & 1 \\
\hline A1 & $86 / 100$ & $100 / 100$ & 1010101010001101000110011 & US- 1.4 & 1 \\
\hline A2 & $100 / 100$ & $100 / 100$ & 1010101000001100001111011 & BR-1 & 7 \\
\hline A2 & $100 / 100$ & $100 / 100$ & 1010101000001100001110011 & BR-1.1 & 27 \\
\hline
\end{tabular}

${ }^{a} \mathrm{Gpi}=$ glucose-6-phosphate isomerase; $P e p=$ peptidase; RG57 probe used for restriction fragment length polymorphism analysis $(\underline{0}=$ putative band). Genotype designation sensu Goodwin et al. (19). 
ately resistant and 41 (55.4\%) were resistant to metalaxyl. For the 48 potato isolates, the number of intermediately resistant and resistant isolates was $8(16.7 \%)$ and $18(37.5 \%)$, respectively.

Two variants of $P$. infestans genotypes, not previously described, were named here as US-1.9 and BR-1.1, according to the criteria proposed by Goodwin et al. (14). The US-1.9 was different from the US-1 in Pep pattern (100/100 instead of 86/100) and for missing band number 9 in the RFLP assay. The BR-1.1 did not have band 22 on the fingerprinting profile using the RG57 probe.

A total of nine multilocus genotypes, based on combinations of the markers in 270 isolates (mating type, Gpi, Pep, and RG57) were identified (Table 2). Of these, two genotypes (US-1 and US-1.4) were isolated from both hosts, four genotypes (US-1.1, US-1.2, US-1.3, and RU-1) were isolated from tomato, and three genotypes (BR-1, BR-1.1, and US-1.9) were isolated from potato.

\section{DISCUSSION}

More than a decade after the first detection of isolates of the A2 mating type of $P$. infestans, isolates of both mating types can be found widespread in southern and southeastern Brazil, indicating the opportunity for sexual reproduction by this plant pathogen. The Brazilian population of $P$. infestans collected in 1998 to 2000 had a clonal structure. A2 isolates always were collected from potato plants, while most A1 isolates (91\%) were found on tomato plants, which indicates a strong host specificity of the lineages of $P$. infestans in Brazil. The few A1 isolates found on potato were from highly susceptible cultivars (Bintje and Monalisa) collected in a region where tomato but not potato is grown commercially. In this traditional tomato-growing area, the A1 isolates infecting potato most likely came from tomato plants due to the high amount of inoculum available.

According to the results of mating, allozyme, and DNA marker tests, isolates of the US-1 lineage are still present in Brazil and were most commonly associated with tomato. Although the specific reasons for host specialization are not certain, there are some possible explanations. One possibility is that there is, indeed, selection by host. Such specialization has been reported in Africa and the United States $(23,37)$. Another explanation is that either or both lineages might be better adapted to the environment in which each host is grown. Tomato plants typically are grown in regions of higher temperature and potato plants typically are grown in regions of lower temperature. We are currently testing the hypothesis that "tomato" isolates respond to temperature differently than "potato" isolates. Finally, another possibility is that genetic drift might have contributed to the current population structure.
The clonal lineage BR-1 probably was introduced to Brazil through seed tubers imported from Europe. There is considerable trade of potato seed with the Netherlands, where sexual recombination can occur and the population of $P$. infestans is very diverse (7). The 100/100 Gpi and $P e p$ patterns found in BR-1 are common in European population of $P$. infestans $(7,11)$. The spread of the BR-1 lineage to other potato-producing areas could have been through potato seed tubers or market potato tubers. The US-1 lineage could have been the dominant lineage on potato in Brazil before the introduction of the A2 isolates. Possibly, the US-1 population on potato was displaced by new A2 genotypes of $P$. infestans, as has been reported in other countries (4,9,22,31).

Some variation on the known profiles of allozymes and RG57 was found within the US-1 lineage. Some of these variants of US-1 also were observed by Goodwin et al. $(15,18)$. These variations (one RFLP band or an allozyme allele) could have resulted from mutation or mitotic recombination (parasexualism). The US-1 variants were not detected in previous surveys in Brazil, but our sample size was much larger and had greater chance of detecting diversity. The US-1.7 genotype, which was detected previously by Goodwin et al. (15), was not found in this study, but we included only one A1 isolate from Rio Grande do Sul State, where US-1.7 originally was isolated.

One isolate was similar to the RU-1 lineage previously found in Russia and Rwanda (15). We do not have a sound explanation for the occurrence of RU-1 in Brazil. Further analysis using more markers is necessary to a better insight on the origin of this isolate.

All isolates of $P$. infestans of the A1 mating type had mtDNA haplotype $\mathrm{Ib}$, which is typical of the US-1 lineage $(2,19)$. This fact supports the hypothesis that the other A1 isolates differing from US- 1 in one or two loci are variants from this lineage and most likely arose by mutation or mitotic recombination. The isolates of the A2 mating type had the IIa mtDNA haplotype, typical of the new lineages, introduced after 1980 (19).

In this study, a high percentage of US-1 isolates $(72.2 \%)$ were resistant or intermediately resistant to metalaxyl, while most of the BR-1 isolates $(44.4 \%)$ were sensitive. This observation differs from results obtained in the United States (10) and Ecuador (9), where most of the isolates

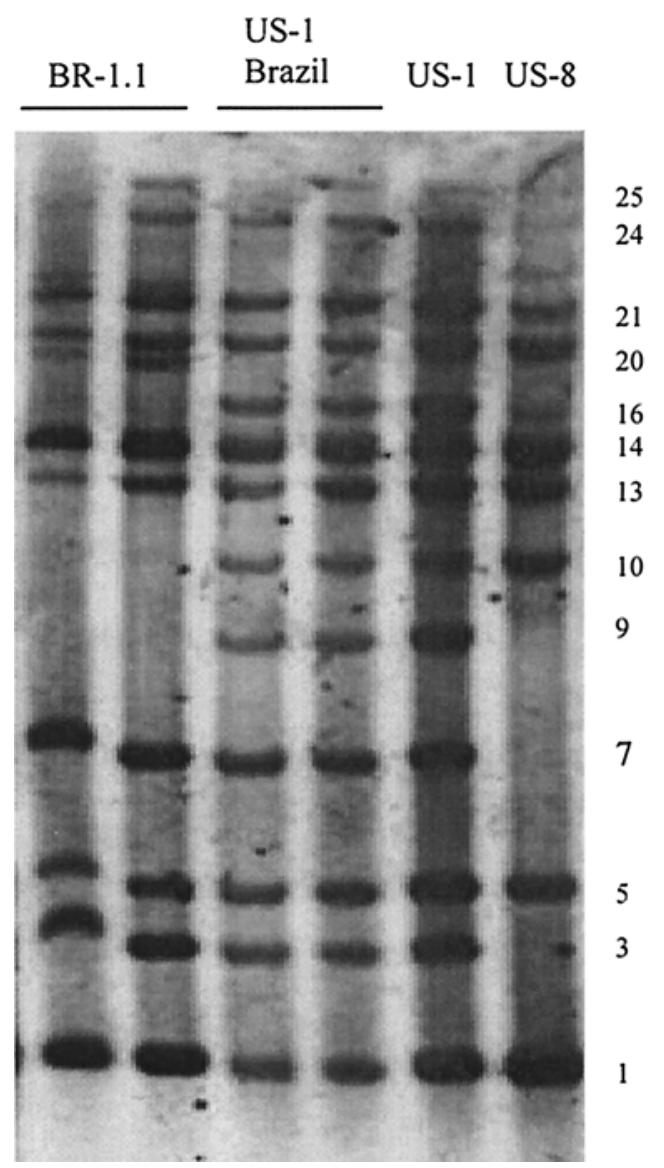

Fig. 2. Autoradiogram of restriction fragment length polymorphism patterns of isolates of Phytophthora infestans using RG57 probe. Lanes 1 and 2, Brazilian isolates of BR-1.1; lanes 3 and 4, Brazilian isolates of the US-1 lineage; lanes 5 and 6, US-1 and US-8 isolates from the Cornell University collection, respectively. RG57 fingerprint band numbers are indicated in the right. 
from the US-1 lineage are metalaxyl sensitive and most of the recently introduced new lineage isolates are metalaxyl resistant. Excessive and inadequate use of metalaxyl on tomato crops is not uncommon in many growing areas in Brazil and could have contributed to the higher frequency of isolates resistant to metalaxyl in tomato than in potato crops.

In spite of the presence of both A1 and A2 mating type of $P$. infestans in Brazil for at least 12 years, the data collected in this study do not indicate sexual reproduction. The population structure remains clonal and there is high host specificity, as observed by Brommonschenkel (1). Several scenarios could contribute to this situation: (i) The lack of sexual reproduction may be due to the host specificity of two clonal lineages, as is the case in Ecuador (28). This characteristic makes the chance of both mating types occurring together rare. (ii) If both A1 and A2 are present and mate, the oospores are not viable, as observed by Mosa et al. (27) in Japan. (iii) If oospores are produced and germinate, the progeny is less adapted than the parental strains and may not survive, as observed by Mayton et al. (25).

\section{ACKNOWLEDGMENTS}

We thank CAPES-Brazil and FAPEMIG for partially supporting this research; EMATER-MG, EMATER-SC, N. R. X. Nazareno, and D. J. Filho for helping with collecting samples; C. B. Gomes (Embrapa Clima Temperado); M. Couto for providing P. infestans isolates from Rio Grande do Sul; and F. H. S. Ribeiro for helping with the metalaxyl resistance work.

\section{LITERATURE CITED}

1. Brommonschenkel, S. H. 1988. Patogenicidade, compatibilidade, citogenética e padrões isoenzimáticos de isolados de Phytophthora infestans (Mont.) DeBary no Brasil. MSc. thesis, Universidade Federal de Viçosa, Brazil.

2. Carter, D. A., Archer, S. A., Buck, K. W., Shaw, D. S., and Shattock, R. C. 1990. Restriction fragment length polymorphisms of mitochondrial DNA of Phytophthora infestans. Mycol. Res. 94:1123-1128.

3. Caten, C. E., and Jinks, J. L. 1968. Spontaneous variability of single isolates of Phytophthora infestans. I. Cultural Variation. Can. J. Bot. 46:329-348.

4. Day, J. P., and Shattock, R. C. 1997. Aggressiveness and other factors relating to displacement of populations of Phytophthora infestans in England and Wales. Eur. J. Plant Pathol. 103:379-391.

5. Deahl, K. L., Inglis, D. A., and DeMuth, S. P. 1993. Testing for resistance to metalaxyl in Phytophthora infestans isolates from Northwestern Washington. Am. Pot. J. 70:779-795.

6. Drenth, A., Janssen, E. M., and Govers, F. 1995. Formation and survival of oospores of Phytophthora infestans under natural conditions. Plant Pathol. 44:86-94.

7. Drenth, A., Turkensteen, L. J., and Govers, F. 1993. The occurrence of the A2 mating type of Phytophthora infestans in the Netherlands; significance and consequences. Neth. J. Plant
Pathol. 99 Suppl. 3:57-67.

8. Erwin, D. C., and Ribeiro, O. K. 1996. Phytophthora Diseases Worldwide. American Phytopathological Society Press, St. Paul, MN.

9. Forbes, G. A., Escobar, X. C., Ayalla, C. C., Revelo, J., Ordoñez, M. E., Fry, B. A., Doucett, K., and Fry, W. E. 1997. Population genetic structure of Phytophthora infestans in Ecuador. Phytopathology 87:375-380.

10. Fry, W. E., and Goodwin, S. B. 1997. Reemergence of potato and tomato late blight in the United States. Plant Dis. 81:1349-1357.

11. Fry, W. E., Goodwin, S. B., Matuszak, J. M., Spielman, L. J., Milgroom, M. G., and Drenth, A. 1992. Population genetics and intercontinental migrations of Phytophthora infestans. Annu. Rev. Phytopathol. 30:107129.

12. Gallegly, M. E., and Galindo, J. 1958. Mating types and oospores of Phytophthora infestans in nature in Mexico. Phytopathology 48:274277.

13. Gavino, P. D., Smart, C. D., Sandrock, R. W., Miller, J. S., Hamm, P. B., Lee, T. Y., Davis, R. M., and Fry, W. E. 2000. Implications of sexual reproduction for Phytophthora infestans in the United States: Generation of an aggressive lineage. Plant Dis. 84:731-735

14. Goodwin, S. B., Cohen, B. A., Deahl, K. L., and Fry, W. E. 1994. Migration from Northern Mexico as the probable cause of recent genetic changes in populations of Phytophthora infestans in the United States and Canada. Phytopathology 84:553-558.

15. Goodwin, S. B., Cohen, B. A., and Fry, W. E. 1994. Panglobal distribution of a single clonal lineage of the Irish potato famine fungus. Proc. Natl. Acad. Sci. USA 91:11591-11595.

16. Goodwin, S. B., Drenth, A., and Fry, W. E. 1992. Cloning and genetic analyses of two highly polymorphic, moderately repetitive nuclear DNAs from Phytophthora infestans. Curr. Genet. 22:107-115.

17. Goodwin, S. B., Schneider, R. E., and Fry, W. E. 1995. Use of cellulose-acetate electrophoresis for rapid identification of allozyme genotypes of Phytophthora infestans. Plant Dis. 79:1181-1185.

18. Goodwin, S. B., Smart, C. D., Sandrock, R. W., Deahl, K. L., Punja, Z. K., and Fry, W. E. 1998. Genetic change within populations of Phytophthora infestans in the United States and Canada during 1994 to 1996: Role of migration and recombination. Phytopathology 88:939-949.

19. Griffith, G. W., and Shaw, D. S. 1998. Polymorphisms in Phytophthora infestans: Four mitochondrial haplotypes are detected after PCR amplification of DNA from pure cultures or from host lesions. Appl. Environ. Microbiol. 64:4007-4014.

20. Hohl, H. R., and Iselin, K. 1984. Strains of Phytophthora infestans from Switzerland with A2 mating type behaviour. Trans. Br. Mycol. Soc. 83:529-531

21. IBGE 2000. Pesquisa mensal de previsão e acompanhamento das safras agrícolas no ano civil. LSPA (Levantamento sistemático da produção agrícola) 12:1-76.

22. Koh, Y. J., Goodwin, S. B., Dyer, A. T., Cohen, B. A., Ogoshi, A., Sato, N., and Fry, W. E. 1994. Migrations and displacements of Phytophthora infestans populations in East Asian countries. Phytopathology 84:922-927.

23. Legard, D. E., Lee, T. Y., and Fry, W. E. 1995. Pathogenic specialization in Phytophthora in- festans: Aggressiveness on tomato. Phytopathology 85:1356-1361.

24. Matuszak, J. M., Fernadez-Elquezabal, J., Gu, W. K., Villareal-Gonzalez, M., and Fry, W. E 1994. Sensitivity of Phytophthora infestans populations to metalaxyl in Mexico: Distribution and dynamics. Plant Dis. 78:911-916.

25. Mayton, H., Smart, C. D., Moravec, B., Mizubuti, E. S. G., Muldoon, A. E., and Fry, W. E. 2000. Oospore survival and pathogenicity of single oospore recombinant progeny from a cross involving US-17 and US-8 genotypes of Phytophthora infestans. Plant Dis. 84:1190-1196.

26. Mizubuti, E. S. G. 2001. Requeima ou mela da batata e do tomate. Pages 100-174 in: Doenças causadas por Phytophthora no Brasil. E. D. N. Luz, A. F. Santos, K Matsuoka, and J. L. Bezerra, eds. Livraria Editora Rural, Campinas, Brazil.

27. Mosa, A. A., Kobayashi, K., Ogoshi, A., Kato, M., and Sato, N. 1993. Isoenzyme polymorphism and segregation in isolates of Phytophthora infestans from Japan. Plant Pathol. 42:26-34.

28. Oyarzun, P. J., Pozo, A., Ordoñez, M. E. Doucett, K., and Forbes, G. A. 1998. Host specificity of Phytophthora infestans on tomato and potato in Ecuador. Phytopathology 88:265-271.

29. Sambrok, J., Fritsh, E. F., and Maniatis, T. 1989. Molecular Cloning: A Laboratory Manual. Cold Spring Harbor Laboratory Press, Cold Spring Harbor, NY.

30. Smart, C. D., Mayton, H., Mizubuti, E. S. G., Willmann, M. R., and Fry, W. E. 2000. Environmental and genetic factors influencing self-fertility in Phytophthora infestans. Phytopathology 90:987-994.

31. Spielman, L. J., Drenth, A., Davidse, L. C., Sujkowski, L. J., Gu, W. K., Tooley, P. W., and Fry, W. E. 1991. A second world-wide migration and population displacement of Phytophthora infestans? Plant Pathol. 40:422430.

32. Spielman, L. J., McMaster, B. J., and Fry, W. E. 1989. Dominance and recessiveness at loci for virulence against potato and tomato in Phytophthora infestans. Theor. Appl. Genet. 77:832-838.

33. Strömberg, A., Persson, L., and Wikström, M. 1999. Infection of potatoes by oospores of Phytophthora infestans in soil. Plant Dis. 83:876.

34. Sujkowski, L. S., Fry, B. A., Power, R. J., Goodwin, S. B., Peever, T. L., Hamlen, R. A and Fry, W. E. 1995. Sensitivities of Mexican isolates of Phytophthora infestans to chlorothalonil, cymoxanil, and metalaxyl. Plant Dis. 79:1117-1120.

35. Therrien, C. D., Tooley, P. W., Spielman, L. J., Fry, W. E., Ritch, D. L., and Shelly, S. E. 1993. Nuclear DNA content, allozyme phenotypes and metalaxyl sensitivity of Phytophthora infestans from Japan. Mycol. Res. 97:945-950.

36. Turkensteen, L. J., Flier, W. G., Wanningen, R., and Mulder, A. 2000. Production, survival and infectivity of oospores of Phytophthora infestans. Plant Pathol. 49:688-696.

37. Vega-Sánchez, M. E., Erselius, L. J., Rodriguez, A. M., Bastidas, O., Hohl, H. R., Ojiambo, P. S., Mukalazi, J., Vermeulen, T. Fry, W. E., and Forbes, G. A. 2000. Host adaptation to potato and tomato within the US-1 clonal lineage of Phytophthora infestans in Uganda and Kenya. Plant Pathol. 49:531-539. 